

Selected Papers of \#AoIR2021: The 22nd Annual Conference of the Association of Internet Researchers Virtual Event / 13-16 Oct 2021

\title{
"I started the day just crying for 2 hours straight." Echo-locating the vulnerable self on Instagram.
}

Author \#1 Maria Schreiber

Author \#1 University of Salzburg

On Instagram, the hashtag "strokesurvivor" is regularly used by those who identify as such, but also by caregivers and professionals. Overall, nearly 246.000 postings are labeled with this hashtag (April 2021). On Instagram, hashtags function as rather loose elements of connecting people, postings and accounts (Rambukkana 2015) compared to disease-specific Facebook groups with admins, content moderation and guidelines (Zhang et al 2013). Building on previous online-ethnographic fieldwork on the \#strokesurvivor-community on Instagram, this contribution dives deeper into practices of echo-locating (Markham 2020) the vulnerable self on Instagram.

The shared traumatic experience of stroke connects a diverse group of people in terms of age, gender, origin etc. Some of the participating accounts were started specifically for stroke recovery documentation or advocacy, others just add the stroke aspect to their existing personal accounts. The level of engagement ranges from active community building to invisible lurking. The self-assigned term and hashtag strokesurvivor functions as a connecting node for the community and their topics, ranging from practical and therapeutical advice or information around stroke recovery and healthcare to disability activism, mutual encouragement and relationship advice, providing opportunities for practices of information management, relationship management and - the focus of this paper - identity management (Schmidt 2006; 2013). The \#strokesurvivor-community seems specifically interesting in terms of identity management as it emerges from a conjunctive existential, life-or-death experience and a shared crisis-laden phase of transition: the sudden loss of mental and/or physical abilities, loss of autonomy and independence, dependency on caregivers and long-term to lifetime recovery. Moreover, this community "lives" within the rather loose, informal and public media ecology of Instagram, which entails different dynamics and affordances than closed, topical, health-related online groups (Maloney-Krichmar \& Preece, 2005; Zhang et al 2013).

The paper therefore investigates communicative online practices of adapting to a new body, identity and self from a symbolic-interactionist perspective. I build on Goffman's

Suggested Citation (APA): Schreiber, M. (2021, October). "I started the day just crying for 2 hours straight." Echo-locating the vulnerable self on Instagram. Paper presented at AoIR 2021: The 22nd Annual Conference of the Association of Internet Researchers. Virtual Event: AolR. Retrieved from http://spir.aoir.org. 
concept of stigma, Charmaz' studies on adapting to illness and impairment and use the lens of Markham's (2020) concept of echo-locating the self through online connection, as it "highlights how people find the shape and quality of their social body by constantly assessing its positionality in relation to others. This is accomplished by a continuous call and response pattern. As people respond to us, we have a sense of a social self. A sense that we exist." - this paper therefore aims to reconstruct the complex practices of positioning oneself as a stroke survivor through communicating on Instagram.

The easy accessibility of online platforms has always been crucial for people with impaired mobility, but became even more important during the recent Covid-19 pandemic. This is also relevant in relation to the AOIR conference's topic: Being able to communicate with other survivors in a self-determined way gives them independence, compared to e.g. needing someone to drive them to a local support group. At the same time, they might become dependent on this online social space to negotiate and express their new identity and body due to the lack of other - offline - social spaces. An additional challenge of echo-locating the vulnerable self on Instagram is the diffuse audience of public postings and a specific kind of context collapse: stroke survivors on Instagram do not communicate with only each other in a closed, safe space for survivors only, they share their experience simultaneously with friends and family, who also know their previous, "non-stroke"-self.

As a stroke survivor myself, I have been following the hashtag on Instagram since September 2018, and started to systematically conduct an digital ethnography on the topic (Ardèvol \& Gómez-Cruz, 2013; Pink et al., 2016; Postill \& Pink, 2012) and collect qualitative data since October 2019, including fieldnotes, screenshots and interviews. The quote used in the title stems from a posting by a young female survivor, in which she negotiates both her pain and grief but also the question whether it is valid to share these feelings on the platform - and how it will be anticipated: "You are probably reading this and [being me] WTF OMG NO." Based on close readings and interpretations of postings, including pictures, captions and comments, as well as interviews with active community members, two critical antipodes of sense- and self-making in the \#strokesurvivor-community emerged:

First, mourning the loss of the familiar body, self, and identity and related identity goals, as "the familiar becomes strange when altered bodies post new constraints, require careful scrutiny, and force attending to time, space, movement, and other people in new ways." (Charmaz 2018: 675). Users therefore seek permission to mourn and also validation for their grief through their postings and comments. Second, and probably oppositional, perseverance, or in its extreme form: toxic positivity - this concept refers to a (more or less forced) attitude of optimism while ignoring valid reasons to actually not be positive, a mindset that seems to be embedded in a "contemporary cult of happiness" (Wright 2014) and cruel optimism (Berlant 2010). In the \#strokesurvivorcommunity, a positive mindset and belief in the possibility of regaining physical and mental functions is a recurring theme and strong imperative. While perseverance is more common and strongly affirmed in the community, practices of mourning are seldom, but welcomed with solidarity; yet in both strategies, the sick or disabled body is not acknowledged as part of the transforming/transformed identity, as the struggle with internalized ableism is real, but not reflected upon. 


\section{References}

Ardèvol, E., \& Gómez-Cruz, E. (2013). Digital Ethnography and Media. In F. DarlingWolf (Ed.), The International Encyclopedia of Media Studies: Research Methods in Media Studies. (pp. 498-518). Wiley-Blackwell.

Berlant, L. (2010). Cruel Optimism. In G. Seigworth \& M. Gregg (Eds.), The Affect Theory Reader (pp. 93-117).

Charmaz, K. (2018). The Body, Identity, and Self : Adapting to Impairment. The Sociological Quarterly, 36(4), 657-680.

Maloney-Krichmar, D., \& Preece, J. (2005). A multilevel analysis of sociability, usability, and community dynamics in an online health community. ACM Transactions on Computer-Human Interaction, 12(2), 201-232.

https://doi.org/10.1145/1067860.1067864

Markham, A. (2020). The Ontological Insecurity of Disconnecting:A Theory of Echolocation and the Self. Draft Paper on https://www.academia.edu/44577011/The_Ontological_Insecurity_of_Disconnecting_A_ Theory_of_Echolocation_and_the_Self (14.4.21)

Pink, S., Horst, H. A., Postill, J., Hjorth, L., Lewis, T., \& Tacchi, J. (2016). Digital ethnography; principles and practice. SAGE Publ.

Postill, J., \& Pink, S. (2012). Social Media Ethnography: The Digital Researcher in a Messy Web. In Media International Australia.

Rambukkana, N. (2015). \#Introduction: Hashtags as technosocial events. Hashtag Publics: The Power and Politics of Discursive Networks, 1-12. https://doi.org/10.3726/978-1-4539-1672-8

Schmidt, J. (2006). Social software: facilitating information-, identity- and relationshipmanagement. In T. N. Burg, \& J.Schmidt (Eds.), BlogTalks reloaded : social software research \& cases (pp. 31-49). Norderstedt: Books On Demand.https://nbnresolving.org/urn:nbn:de:0168-ssoar-10215

Schmidt, J.-H. (2013). Practices of Networked Identity. In A Companion to New Media Dynamics (pp. 365-374). https://doi.org/10.1002/9781118321607.ch24

Wright, C. (2014). Happiness Studies and Wellbeing: A Lacanian Critique of Contemporary Conceptualisations of the Cure. Culture Unbound, 6(4), 791-813. https://doi.org/10.3384/cu.2000.1525.146791

Zhang, Y., He, D., \& Sang, Y. (2013). Facebook as a platform for health information and communication: A case study of a diabetes group. Journal of Medical Systems, 37(3). https://doi.org/10.1007/s10916-013-9942-7 